\title{
BMJ Open Perceptions of patient safety culture among medical students: a cross- sectional investigation in Heilongjiang Province, China
}

\author{
He Liu, ${ }^{1,2}$ Ying Li, ${ }^{1}$ Siqi Zhao, ${ }^{3}$ Mingli Jiao, ${ }^{1,4}$ Yan Lu, ${ }^{5}$ Jinghua Liu, ${ }^{6}$ Kexin Jiang, ${ }^{1}$ \\ Huiying Fang, ${ }^{1}$ Peihang Sun, ${ }^{1}$ Peng Li, ${ }^{1}$ Yameng Wang, ${ }^{1}$ Haonan Jia, ${ }^{1}$ Yuming Wu, ${ }^{7}$ \\ Limin Liu, ${ }^{8}$ Yanming Zhao, ${ }^{9}$ Qunhong Wu ${ }^{10}$
}

To cite: Liu H, Li Y, Zhao S, et al. Perceptions of patient safety culture among medical students: a cross-sectional investigation in Heilongjiang Province, China. BMJ Open 2018;8:e020200. doi:10.1136/ bmjopen-2017-020200

- Prepublication history for this paper is available online. To view these files, please visit the journal online (http://dx.doi org/10.1136/bmjopen-2017020200).

$\mathrm{HL}$ and $\mathrm{YL}$ contributed equally.

Received 20 0ctober 2017

Revised 18 May 2018 Accepted 19 June 2018

Check for updates

(C) Author(s) (or their employer(s)) 2018. Re-use permitted under CC BY-NC. No commercial re-use. See rights and permissions. Published by BMJ.

For numbered affiliations see end of article.

Correspondence to Dr Mingli Jiao; minglijia0@126.com and Dr. Qunhong Wu; wuqunhong12345@163.com

\section{ABSTRACT}

Objectives Medical school education plays an important role in promoting patient safety. In this study, we assess medical students' perceptions of patient safety culture, identify their educational needs and provide evidence on the most important content relating to patient safety for the medical school curriculum.

Method This cross-sectional study was conducted in four medical universities in Heilongjiang province. Medical students in the first through five years completed an anonymous questionnaire-the Attitudes toward Patient Safety Questionnaire III. We analysed the differences in responses across the four universities and their cohorts. Results The overall perceptions of patient safety culture across the four medical universities were positive. The highest positive response rate was for 'I have a good understanding of patient safety issues as a result of my undergraduate medical training' (range: 58.4\%-99.8\%), whereas the lowest positive response rate was for 'medical errors are a sign of incompetence' (14.7\%$47.9 \%$ ). Respondents in the earlier years of school tended to have more positive responses for items concerning working hours and team work; however, fourth and fifth year students had more positive responses for error inevitability. Items with the lowest positive response rates across the cohorts included items related to 'professional incompetence as a cause of error' and 'disclosure responsibility'.

Conclusions While students generally had positive views of patient safety culture, none of them had been exposed to any formal curriculum content on patient safety. Policymakers should focus more on how educational needs vary across schools and cohorts in order to establish appropriate curricula.

\section{INTRODUCTION}

Providing patients with a safe and comfortable medical environment is an important task for medical and healthcare organisations worldwide. Indeed, in 1999, the Institute of Medicine (IOM) released a report called 'To Err Is Human: Building a Safer Health System' to highlight the importance of
Strengths and limitations of this study

- This is the first study to use the Attitudes toward Patient Safety Questionnaire III to compare patient safety culture across different medical schools and grades in Heilongjiang province, China.

- We covered almost all the medical colleges in Heilongjiang province.

- The study is limited by the potential non-response bias. Students who responded to the survey might have been more interested than their peers in patient safety, which might have inflated the attitude ratings.

- The results might not be generalisable to all medical colleges in China, although our sample size was large.

patient safety. ${ }^{1}$ Studies conducted in several countries have shown that a lack of attention to patient safety can lead to medical errors, which in turn can harm patients and increase their hospitalisation time. ${ }^{23}$ Hence, the maintenance and promotion of patient safety is of utmost importance.

The advancement of patient safety requires a fundamental change in the healthcare culture. Reducing harm through an improved safety culture is a global priority. ${ }^{4}$ Policymakers, payers and groups such as the Agency for Healthcare Research and Quality, National Patient Safety Agency and WHO have developed numerous safety initiatives at the national and institutional levels. ${ }^{5}$ However, most of these initiatives targeted doctors, managers and other healthcare professionals and rather less attention has been paid to medical students, who are the next generation of medical workers. ${ }^{6}$ It is essential for medical students to have a good understanding of the patient safety culture because it will doubtlessly influence their 
attitude towards patient safety issues throughout their working lives

In 1980, Hilfiker reported that medical graduates lack the ability to handle medical errors. ${ }^{7}$ Even by 1998, Pilpel and his colleagues found that there was not yet any formal document for medical students that described how to handle medical errors. ${ }^{8}$ While the launch of the 'Building a Safer Health Care System' in 1999 triggered a global discussion of patient safety issues, ${ }^{1}$ a later study by Leape et al concluded that the status of patient safety education is not optimal. ${ }^{9}$ The Australian Health Safety and Quality Committee published the National Patient Safety Education Framework (NPSF) in 2005. ${ }^{10}$ Then, in 2008, the WHO constituted the first expert committee on patient safety issues in undergraduate medical curricula. ${ }^{11}$ Subsequently, the Patient Safety Alliance conducted pilot studies in 11 schools worldwide, and proposed that advocacy for patient safety activities is one of the most important WHO initiatives in the 21 st century globally.

The primary prerequisite for the implementation of education on patient safety culture is to understand medical students' current awareness of safety culture. To this end, Carruthers et al used the Attitudes toward Patient Safety Questionnaire (APSQ) to study medical students' perceptions of the patient safety culture. ${ }^{12}$ Similarly, Liao et al surveyed 367 medical students at three medical colleges in the United States about the patient safety culture, ${ }^{5}$ while Bowman et al explored knowledge of patient safety culture among 170 medical students at the University of California at San Francisco. ${ }^{13}$ Leung et al surveyed second year students at medical schools in Hong Kong and Singapore about their perceptions of patient safety culture and compared their different educational needs. ${ }^{14}$ However, patient safety education in areas with low medical standards and high medical risks-for example, in developing countries like China-is still in its infancy. ${ }^{15}$ One thing we do understand, from a report exploring safety education content and teaching methods in China, ${ }^{16}$ is that patient safety education has not been fully implemented within the curricula and clinical practice therein.

Heilongjiang province, as the healthcare centre of Northeast China, has the largest area and availability of health resources, with a population of more than 30 million people. ${ }^{17}$ Heilongjiang province has four prominent medical schools that provide medical and health service personnel training for the entire province: Harbin Medical University, Qiqihar Medical University, Mudanjiang Medical University and the Medical College of Jiamusi University. Of these, Harbin Medical University has the best reputation for education and most stringent entrance requirements, although the others (along with their affiliated tertiary hospitals) enjoy a good reputation as well. However, there are no studies examining perceptions of patient safety culture among medical students in Heilongjiang province, and few in China as a whole. Understanding current perceptions of patient safety culture and identifying medical students' most urgent educational needs in that area is critical for the effective design and successful implementation of education programmes at Heilongjiang's medical institutions. Consequently, we evaluated the students' perceptions of the patient safety culture at these four medical schools, with the goal of identifying domains critical to transforming patient safety perspectives and addressing students' educational needs.

\section{METHODS}

\section{Sampling and data collection}

In 2014, we conducted a cross-sectional survey of four medical schools in Heilongjiang province. The cooperation of the schools was obtained by contacting the managers of the student affairs offices. While some of these schools offered courses in doctor-patient relations and evidence-based medicine, none of them had a dedicated or systematic patient safety course. Furthermore, none of the students had received any prior formal teaching on patient safety. As such, we could obtain a baseline assessment of these students' views on the patient safety culture. We used systematic random sampling to select 800 clinical medical students from a roster of all medical undergraduates at each school. We provided these students with detailed explanations of the objective of this investigation; some students expressed interest in participating in the survey, while others declined to participate. Students who were willing to participate were given 2 days to complete the questionnaire anonymously, after which they returned it to a box provided in a counsellor's office. We did not collect respondents' names or any other identifiers. Using this procedure, we obtained 2498 valid questionnaires (total response rate: $78.1 \%$ ). Of the students who participated, 726 (response rate: $90.8 \%$ ) came from Harbin Medical University, 631 (78.9\%) from Qiqihar Medical University, 459 (57.4\%) from Mudanjiang Medical University and 682 (85.3\%) from the Medical College of Jiamusi University.

\section{Questionnaire}

We used the APSQ-III, ${ }^{12} 14{ }^{18-20}$ which was specifically designed for students and covers nine key domains related to patient safety culture. The APSQ-III assesses several domains regarding patient safety culture, rather than examining differences in patient safety education. As such, it can more accurately reflect realistic educational needs. ${ }^{14}$ The APSQ-III has a stable domain structure and criterion validity; it can also distinguish between diverse student subgroups. ${ }^{14}$

The questionnaire comprises 26 items covering nine key patient safety domains:

a. Patient safety training received (items 1-3) .

b. Error reporting confidence (items 4-6).

c. Working hours as an error cause (items 7-9).

d. Error inevitability (items 10-12).

e. Professional incompetence as an error cause (items 13-16). 
f. Disclosure responsibility (items 17-19).

g. Team functioning (items 20 and 21).

h. Patient involvement in reducing error (items 22 and 23).

i. Importance of patient safety in the curriculum (items 24-26).

\section{Data analyses}

Responses were recorded on a five-point Likert scale ( $5=$ strongly agree and $1=$ strongly disagree). Responses were grouped into agree (ie, 4 or 5 ) and disagree (ie, 1 or 2 ), and overall percentages were obtained. ${ }^{14}$ An analysis of variance was used to compare the positive responses rate among students in different years of medical school. We also excluded unanswered questions from the analyses. The significance was set at $\mathrm{P}<0.05$.

\section{Patient and public involvement}

Patients and public are not involved in the process of this study. As described in more detail in the methods section, we investigated the understanding of patient safety culture by medical students. The participants will be informed of the study results via lectures in their schools.

\section{RESULTS}

Of the students who responded to the demographic questions, 1055 (42.4\%) were male, and 1435 (57.4\%) were female. The response rates varied among the school year cohorts: first year, 399 (16\%); second year, 483 (19.3\%); third year, 587 (23.5\%); fourth year, 746 (29.9\%); and fifth year, $283(11.3 \%)$ (table 1$)$.

Table 2 summarises the patient safety culture perceptions, by survey domain, for the total sample and the four subgroups by medical school. The overall highest positive response rates were for the following domains: 'patient safety training received', 'patient involvement in reducing errors', 'I have a good understanding of patient safety issues as a result of my undergraduate medical training' and 'patients have an important role in preventing medical errors'. The lowest positive response rates were for the domains 'professional incompetence as an error cause', 'disclosure responsibility', 'medical errors are a sign of incompetence' and 'it is not necessary to report errors, which do not result in adverse outcomes for the patient'.

When looking at specific medical schools, the highest positive response rates were found in Mudanjiang Medical College for the domain 'patient safety training received'. Jiamusi Medical College had the second highest rates overall, and its highest positive response rate was for the domain 'working hours as an error cause'. In Qiqihar Medical University, the highest positive response rate was for 'patient involvement in reducing errors'. In all four institutions, the lowest positive response rate was for 'professional incompetence as an error cause'. The overall lowest positive response rates came from Harbin Medical University; the highest positive response rate was for the domain 'patient safety training received' and the lowest for 'error reporting confidence'. We observed statistically significant differences among the schools in their responses to all nine key patient safety domains.

Table 3 summarises the patient safety culture perceptions for the total sample and five school-year cohorts, according to the APSQ-III domains. Perceptions of patient safety culture varied noticeably according to school year. All five cohorts had a positive perception of 'patient safety training received' and 'patient involvement in reducing errors'. However, first and second year students had more positive perceptions of 'working hours as an error cause', while third year students had a more positive view of 'team functioning'. Besides the aforementioned domains, fourth and fifth year students had high positive response rates for 'error inevitability'. The lowest positive response rates were for 'professional incompetence as an error cause' and 'importance of patient safety in the curriculum' for all cohorts. As shown in table 4, there was a significant difference $(\mathrm{p}<0.05)$ among cohorts in their positive response rates for "patient safety training

Table 1 Respondents' demographic characteristics

\begin{tabular}{|c|c|c|c|c|}
\hline \multirow[b]{2}{*}{ Characteristic } & \multicolumn{4}{|l|}{ n (\%) } \\
\hline & A & B & C & D \\
\hline \multicolumn{5}{|l|}{ Gender } \\
\hline Female & $404(55.6)$ & 366 (58.3) & $292(63.6)$ & $377(55)$ \\
\hline \multicolumn{5}{|c|}{ Year in medical school } \\
\hline Second & 132 (18.2) & $146(23.1)$ & $115(25.1)$ & $90(13.2)$ \\
\hline Third & $154(21.2)$ & $117(18.5)$ & $110(24)$ & $206(30.2)$ \\
\hline Fourth & $245(33.7)$ & $100(15.9)$ & $131(28.5)$ & $270(39.6)$ \\
\hline Fifth & $84(11.6)$ & $82(13)$ & $67(14.6)$ & $50(7.3)$ \\
\hline
\end{tabular}

A, Harbin Medical University; B, Qiqihar Medical University; C, Mudanjiang Medical University; D, Medical College of Jiamusi University. 


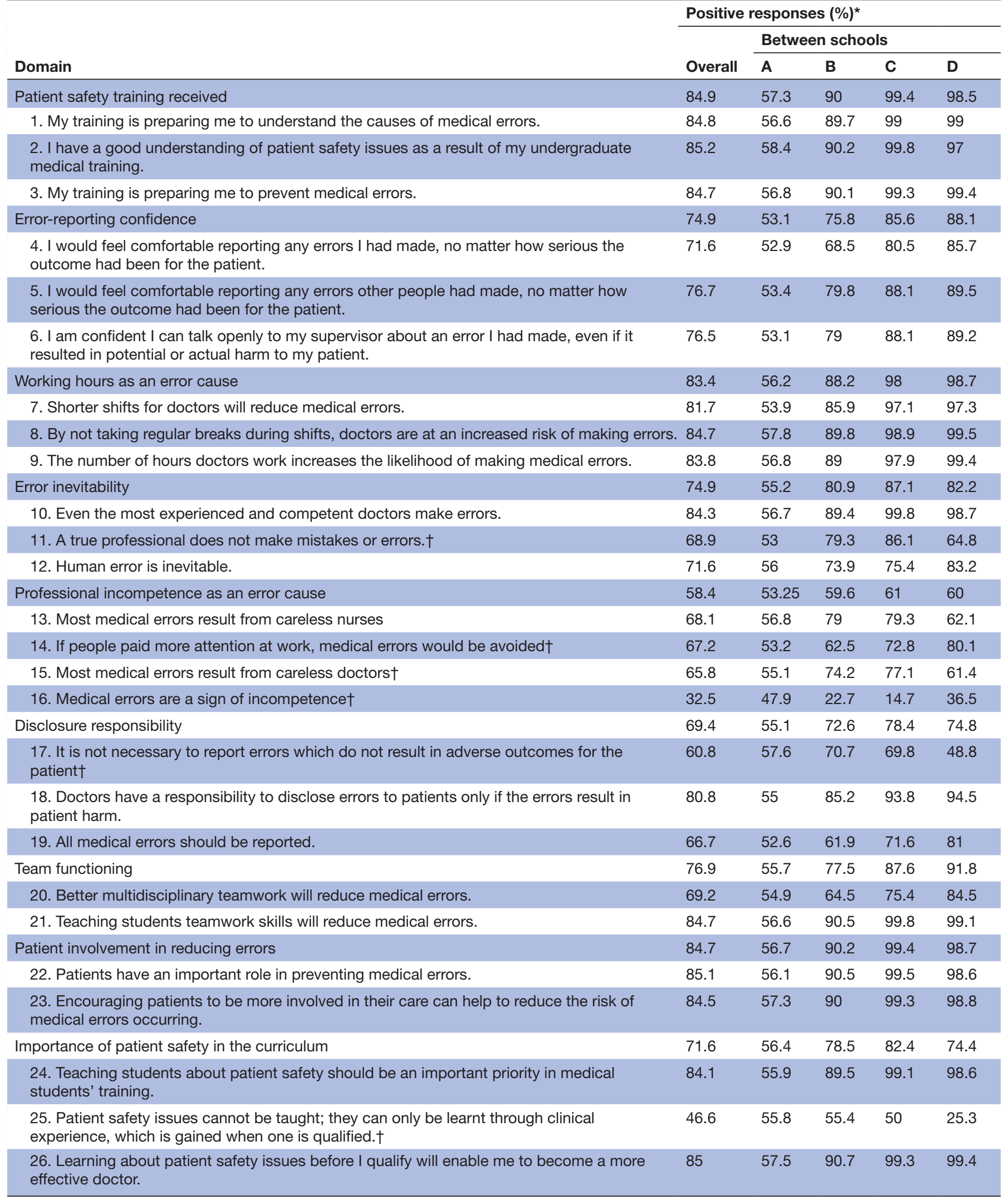

A, Harbin Medical University; B, Qiqihar Medical University; C, Mudanjiang Medical University; D, Medical College of Jiamusi University. *Positive responses include responses of 'agree' or 'strongly agree'. The denominator for each question might vary because some students did not respond to every question in the survey;

†Negatively worded item, where the positive response rate is based on responses of 'strongly disagree' or 'disagree'.

APSQ-III, Attitudes toward Patient Safety Questionnaire III. 


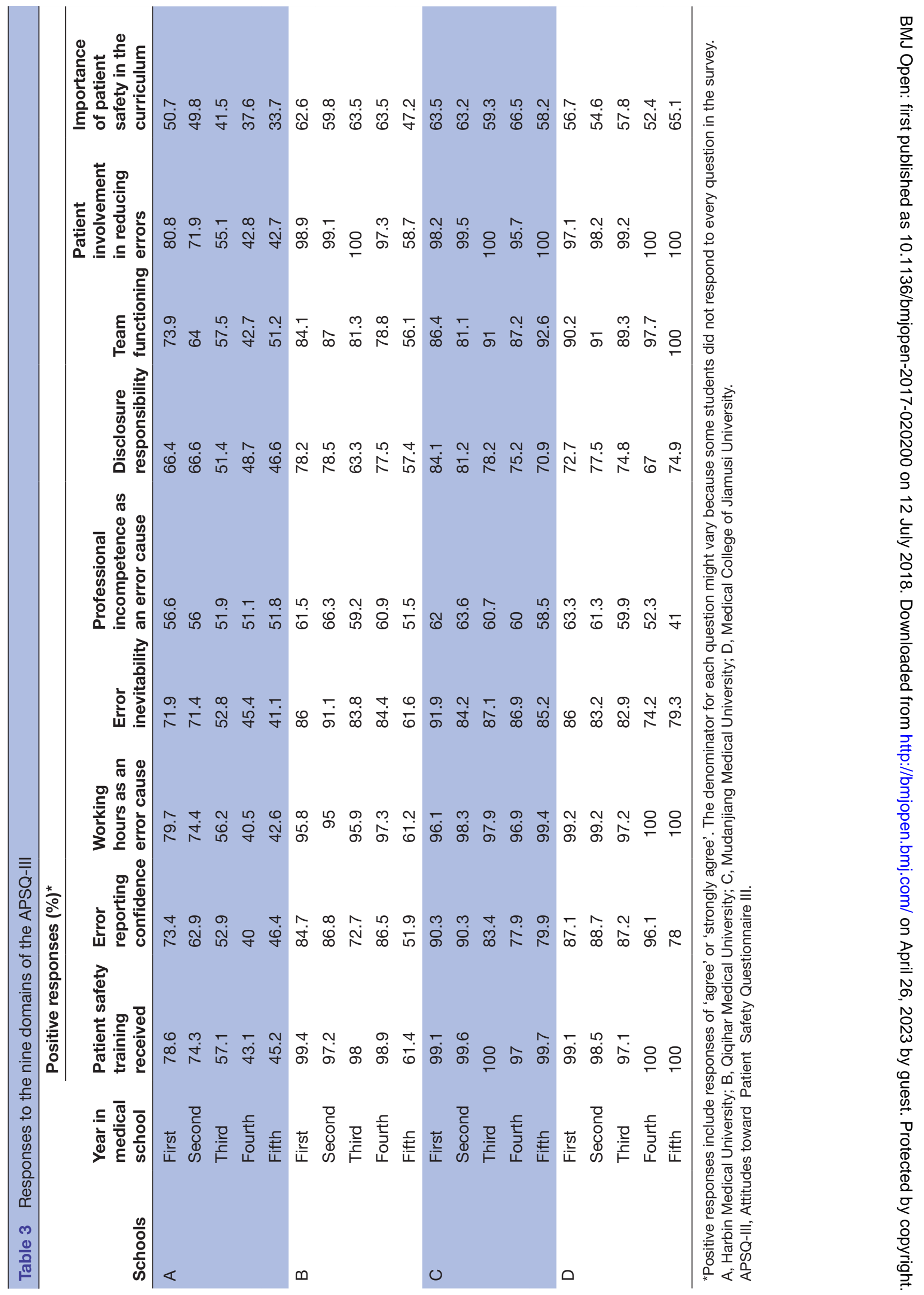




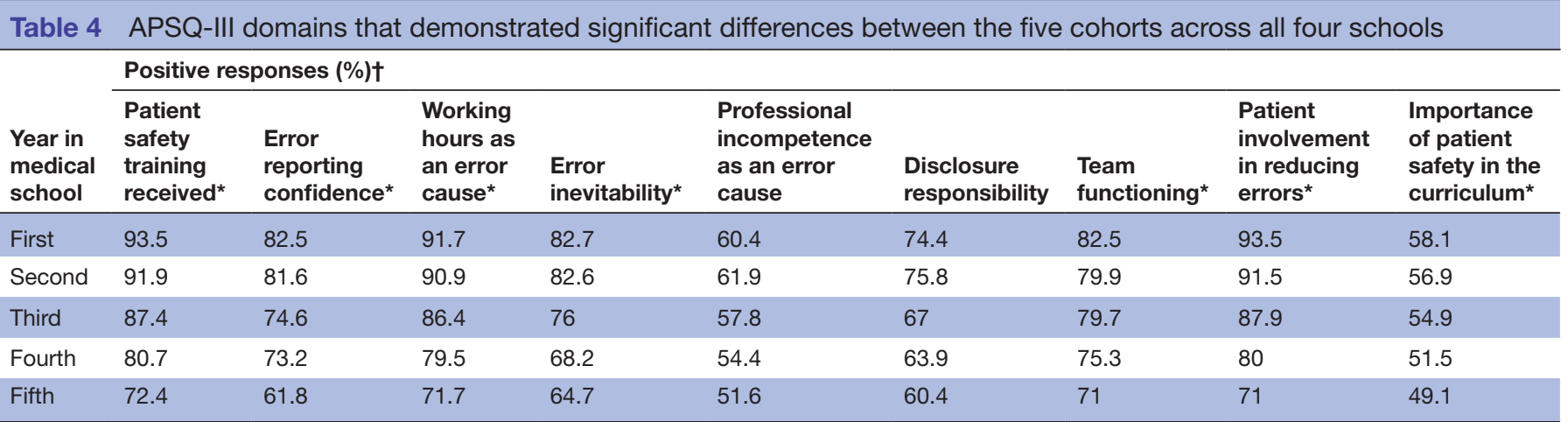

${ }^{*} \mathrm{P}<0.05$.

†Positive responses include responses of 'agree' or 'strongly agree'. The denominator for each question might vary because some students did not respond to every question in the survey.

APSQ-III , Attitudes toward Patient Safety Questionnaire III.

received', 'error reporting confidence', 'working hours as an error cause', 'error inevitability', 'team functioning', 'patient involvement in reducing errors', and 'importance of patient safety in the curriculum'.

\section{DISCUSSION}

Patient safety is a top healthcare priority, and all medical undergraduates must have the necessary capacity to minimise patient harm as they embark on their future career. Education and training are key to achieving this goal. ${ }^{5}$ Medical students' experiences at medical school, as well as their perceptions about the patient safety culture, have an important influence on their attitudes toward patient safety and their behaviours within this domain. ${ }^{21}$ Therefore, screening their perceptions of the key areas of patient safety, as in the present study, offers an opportunity to improve their clinical acumen and future medical education. It can also be utilised by medical directors and clinical service supervisors for real-time assessment in promoting a safety culture. We also conducted the present study to demonstrate how the APSQ-III can be used to identify differences among school-year cohorts across several medical universities in Northeast China.

The findings of this study highlight that medical students tend to have generally positive perceptions of the patient safety culture. ${ }^{22}$ Interestingly, although none of our participants had received any formal teaching on the subject, students from all four universities tended to report that they had been trained in this subject well $(84.9 \%)$. This finding is similar to that of a previous study by Leung et al in Hong Kong, ${ }^{14}$ who proposed that the result could be due to students' misunderstanding or an inability to distinguish teaching from they have learnt from public media. We also believe that this is because of a rather common psychological phenomenon among students in China-that is, escaping responsibility. This phenomenon refers to the idea that Chinese students are struggling to cope with and protect themselves in an intensely hierarchical environment, which manifests as a fear of telling the truth because of its potential impact on teachers' evaluations of them. Accordingly, many students do not want to acknowledge errors or defects, and may be unwilling to report problems to avoid poor evaluations or to fit in within their teams. ${ }^{5}$ Therefore, more attention should be paid to this reluctance to 'speak up' in Chinese culture, and greater vigilance is required to prevent the fear of exposing deficiencies.

Leung et al found the highest positive response rates for 'working hours as an error cause', 'error inevitability' and 'importance of patient safety in the curriculum', whereas 'patient involvement in reducing error' and 'team functioning' had the lowest overall positive response rates. ${ }^{14}$ By contrast, in the present study, 'patient involvement in reducing errors' and 'patient safety training received' had the highest positive response rates, while 'professional incompetence as an error cause' and 'disclosure responsibility' had the lowest. In contrast with students in Hong Kong, students in mainland China responded positively to items relating to 'patient involvement in reducing errors'. A probable reason for this finding is that patients in Hong Kong must adhere to the illness-specific arrangements made by public medical institutions regarding waiting lists, hospitalisation and surgery. Additionally, they cannot choose their own doctors (however, they are generally trusting of doctors and hospitals). In mainland China, however, patients' understanding of their diagnosis and treatment has been continuously improving, and the traditional medical model is gradually being replaced with more active patient participation. ${ }^{23}$ The doctor and patient undertake the process of medical decision-making together, and the patient has the right to choose their doctor independently. In addition, medical staff in mainland China often encourage patients and their families to participate in diagnosisand treatment-related procedures. ${ }^{24}$ This might include encouraging patients or family members to participate in examining the label on an infusion bottle to obtain the name of the drug, reading drug information and so on. Previous research has shown that patient participation can reduce the occurrence of medical errors. ${ }^{25}$ All these 
points might explain why Chinese medical students show positive attitudes for this domain.

We found that responses to the 'professional incompetence as an error cause' domain were more negative compared with responses in the other domains, especially for the following items: 'medical errors are a sign of incompetence' (32.5\%), 'medical students generally consider errors as inevitable' $(74.9 \%)$ and 'even the most experienced and competent doctors make errors' $(84.3 \%)$. These findings suggest that students lack a proper understanding of the causes for certain errors. Our results are similar to those of Moskowitz et al, who found that students in the USA were uncertain as to what constituted an error and what caused errors. ${ }^{18}$

Medical students generally agreed that medical errors are caused by humans and a sign of incompetence $(32.5 \%)$, showing that they lacked awareness about systematic errors. Furthermore, a number of students agreed that long working hours and medical staff incompetence were important causes of errors. This finding indicates that the students emphasised human factors in judging the causes of errors, which aligns with findings from a previous study on students from Hong Kong: in that study, most students reported that 'if they work hard, they can eliminate errors' was an effective strategy for preventing future errors. ${ }^{26}$ These findings suggest a need for emphasising the potential role of other factors (eg, systemic errors and procedural complexity) during the occurrence of medical errors.

Several students reported positive perceptions of their error reporting confidence, but had less positive perceptions of their responsibility for reporting (ie, what and how to report a problem with patient care when they witness it). Their highly positive views on reporting medical errors $(74.9 \%)$ are similar to the results of a Turkish study conducted by Karaoglu et $a l^{27}{ }^{28}$ who found that $60.7 \%(n=147)$ of students stated that they would report an error to the hospital committee if they had made it themselves. Furthermore, $68.6 \%(n=166)$ of the students in that study stated that they would report a medical error if they witnessed one.

In Flin $e t$ als study, most students reported that they would speak up about an error. However, this result was somewhat confusing, since students also had high positive response rates for the item, 'it is not necessary to report errors that do not result in adverse outcomes for the patient' $(60.8 \%) .{ }^{29}$ More than $50 \%$ of the students attending the Medical College at Jiamusi University agreed with this statement. All members of the medical team, including medical students, should be able to recognise unsafe conditions, report errors and strive to improve error disclosure in settings where it is lacking. This persistent cultural change should contribute to the eradication of errors and reduce patient safety concerns. ${ }^{30-32}$

Numerous students agreed with the following statements: 'my training is preparing me to understand the causes of medical errors' (84.8\%) and 'I have a good understanding of patient safety issues because of my undergraduate medical training' $(85.2 \%)$. This finding illustrates that medical students tend to have grand expectations regarding patient safety education, which is in line with the findings of Madigosky et al..$^{33}$ This US-based study also revealed that awareness of patient safety and medical errors can be increased and sustained via an experiential curriculum, which students rated as a valuable experience. ${ }^{1333}$

Insights can be gleaned from the differences observed among the four medical schools. The four universities ranked as follows in their positive response rates, in descending order: Mudanjiang Medical University, the Medical College of Jiamusi University, Qiqihar Medical University and Harbin Medical University. Notably, we found no evidence of different reporting practices between the four medical schools. Possibly, the differences in local patient safety cultures, as well as students' social and cultural backgrounds, are significant contributing factors to these different positive response rates. ${ }^{30}$ However, the present study design did not enable an exploration of these factors; we could only determine the focal aspects of future teaching. For example, Mudanjiang Medical University, the Medical College of Jiamusi University, and Qiqihar Medical University might target education toward the classification and underlying mechanisms of medical errors. In contrast, Harbin Medical University might target students' confidence in error reporting as an area for improvement.

Our results run counter to those from other countries. For example, Flin et al's study in the UK found that most first-year students reported 'medium low' or 'average' levels of knowledge regarding errors and patient safety issues. ${ }^{34-38}$ Our results revealed that positive perceptions of a patient safety culture tended to decrease as students progressed through medical school. As seen in table 3, more senior students appeared to have less positive perceptions of 'error reporting confidence' and 'the importance of patient safety in the curriculum'. Possible reasons for these findings include senior students' experience of working in strong clinical hierarchies, which is known to have a negative influence on error reporting and disclosure of medical errors. ${ }^{39}$ Furthermore, this decrease in medical error disclosure might emerge as a result of increasing awareness and more realistic self-assessment that students develop during the process of medical education. ${ }^{40}$ It could also be the result of inadequate training and preparation of young doctors. More senior students also appeared to have less positive perceptions of 'the importance of patient safety in the curriculum'. A likely reason for this finding is that because students face an increasing number of courses and pressure of examinations as they progress from their first to their fifth year, they do not want to add new courses to their curriculum. Still, the precise reason for this remains to be determined.

A limitation of this study is the possible non-response bias. Students who agreed to respond to the survey might 
have been more interested in patient safety than their non-responding peers. This greater level of interest might have led to the inflation of attitude ratings. Another limitation is that we made use of a non-standardised survey instrument. In addition, the APSQ-III is a self-assessment questionnaire that addresses students' own perceptions of a patient safety culture rather than their actual teachings in this area. Therefore, the present results might not be indicative of students' actual skills and knowledge. Moreover, extrapolation of our findings to other medical colleges should be done with caution. Nevertheless, this is the first use of the APSQ-III to compare patient safety cultures across different schools and school-year cohorts within mainland China. While the present sample was taken from only one region in China, we covered almost all the medical colleges within this rather large province. Furthermore, we recruited a cohort of medical students across all 5 years of their programmes; therefore, this study represents an important advancement in research on patient safety education in China. We believe that our findings can help educators develop suitable curricula for a patient safety education.

In conclusion, our study explored perceptions of the patient safety culture among medical students in China. These findings suggest that medical students' perceptions of patient safety culture can provide a tool for guiding medical education. Institutions should focus more on issues related to the causes of medical errors and error reporting. Shifts in patient safety culture should also be based on situations affecting different schools and cohorts, especially among third-year medical students. Longitudinal studies using a validated instrument should also be conducted to better evaluate patient safety education programmes and their relative impact on local healthcare development. Further studies should also explore the culture of reporting errors and how students in nursing and healthcare education programmes address these errors.

\section{Author affiliations}

${ }^{1}$ Department of Health Policy and Hospital Management, School of Public Health, Harbin Medical University, Harbin, China

${ }^{2}$ Office of Academic Affairs, Hebei Medical University, Shijiazhuang, China

${ }^{3}$ Department of Psychology and Humanities Nursing, Hebei Medical University, Shijiazhuang, China

${ }^{4}$ Institute of Quantitative and Technical Economics, Chinese Academy of Social Science, Beijing, China

${ }^{5}$ School of Public Health, Jiamusi University, Jiamusi, China

${ }^{6}$ School of Public Health, Qiqihar Medical University, Qiqihar, China

${ }^{7}$ Department of Physiology, School of Masic medicine, Hebei Medical University, Shijiazhuang, China

${ }^{8}$ Medical Record Room, The 2nd Affiliated Hospital of Harbin Medical University, Harbin, China

${ }^{9} \mathrm{CT}$ Room, The 2nd Affiliated Hospital of Harbin Medical University, Harbin, China ${ }^{10}$ Department of Social Medicine, School of Public Health, Harbin Medical University, Harbin, China

Contributors MJ, QW, YL and HL. designed the study; JL, LL, YZ, KJ, HF, PS, PL, YW, HJ and YL collected the data; HL, YL and YW analysed the data; HL, YL, MJ and SZ drafted the manuscript; and MJ contributed to the manuscript's revision. All authors approved the final manuscript for publication.
Funding This study was funded by the Natural Science Foundation of China (71273002, 71473064); the New Century Excellent Talents of University at the Ministry of Education, China (1252-NCET02); the China Postdoctoral Science Foundation (2015M570211, 2016T90181); and Collaborative Innovation Centre of Social Risks Governance in Health;Project of Education Department of Heilongjiang Province(Education Reform Project, JGXM_HLJ_2014087);Social science association of Heilongjiang Province(15058).

Competing interests None declared.

Patient consent Not required.

Ethics approval Ethics Committee of Harbin Medical University.

Provenance and peer review Not commissioned; externally peer reviewed.

Data sharing statement Data are available from the corresponding author upon request.

Open access This is an open access article distributed in accordance with the Creative Commons Attribution Non Commercial (CC BY-NC 4.0) license, which permits others to distribute, remix, adapt, build upon this work non-commercially, and license their derivative works on different terms, provided the original work is properly cited, appropriate credit is given, any changes made indicated, and the use is non-commercial. See: http://creativecommons.org/licenses/by-nc/4.0/.

\section{REFERENCES}

1. Kohn LT, Corrigan JM, Donaldson MS. Institute of Medicine. To err is human: building a safer health system. AnnalesFrancaises $D$ Anesthesie Et De Reanimation 2000;7:245-6.

2. de Vries EN, Ramrattan MA, Smorenburg SM, et al. The incidence and nature of in-hospital adverse events: a systematic review. Qual Saf Health Care 2008;17:216-23.

3. Huang DT, Clermont G, Kong L, et al. Intensive care unit safety culture and outcomes: a US multicenter study. Int J Qual Health Care 2010;22:151-61.

4. Willeumier D. Advocate health care: a systemwide approach to quality and safety. Jt Comm J Qual Saf 2004;30:559-66.

5. Liao JM, Etchegaray JM, Williams ST, et al. Assessing medical students' perceptions of patient safety: the medical student safety attitudes and professionalism survey. Acad Med 2014;89:343.

6. Kirch DG, Boysen PG. Changing the culture in medical education to teach patient safety. Health Aff 2010;29:1600-4.

7. Hilfiker D. Facing our mistakes. N Engl J Med 1984;310:118-22.

8. Pilpel D, Schor R, Benbassat J. Barriers to acceptance of medical error: the case for a teaching program (695). Med Educ 1998;32:3-7.

9. Leape LL, Berwick DM. Five years after To Err Is Human: what have we learned? JAMA 2005;293:2384-90.

10. Walton MM, Shaw T, Barnet S, et al. Developing a national patient safety education framework for Australia. Qual Saf Health Care 2006;15:437-42.

11. WHO Patient Safety Curriculun Guide for Medical Schools. 2009 http://www.who.int/patient/education/curriculum/download/en/index. html.

12. Carruthers S, Lawton R, Sandars J, et al. Attitudes to patient safety amongst medical students and tutors: Developing a reliable and valid measure. Med Teach 2009;31:e370-6.

13. Bowman $\mathrm{C}$, Neeman $\mathrm{N}$, Sehgal NL. Enculturation of unsafe attitudes and behaviors: student perceptions of safety culture. Acad Med 2013;88:802-10.

14. Leung GK, Ang SB, Lau TC, et al. Patient safety culture among medical students in Singapore and Hong Kong. Singapore Med J 2013;54:501-5.

15. Zhang M, Duan Y, Li J, et al. Patient Safety Education: One of the Important Topics for 21st Medical Education. Chinese Journal of Evidence-Based Medicine 2010;10:637-9.

16. Walton MM, Barraclough BH, Van Staalduinen SA, et al. An educational approach to improving healthcare safety and quality. $J$ Evid Based Med 2009;2:136-42.

17. China Statistical Yearbook of health and family planning. National Health and Family Planning Commission of the People's Republic of China. China: Union Medical University Press, 2014.

18. Sexton JB, Helmreich RL, Neilands TB, et al. The Safety Attitudes Questionnaire: psychometric properties, benchmarking data, and emerging research. BMC Health Serv Res 2006;6:44.

19. Wiggleton C, Petrusa E, Loomis K, et al. Medical students' experiences of moral distress: development of a web-based survey. Acad Med 2010;85:111-7.

20. Etchegaray JM, Gallagher TH, Bell SK, et al. Error disclosure: a new domain for safety culture assessment. BMJ Qual Saf 2012;21:594-9. 
21. Agency for Healthcare Research and Quality. Hospital Survey on Patient Safety Culture. http://www.ahrq.gov/qual/ patientsafetyculture/hospsurvindex.htm (accessed 17 Oct 2013).

22. Edition T. Principles and practice of structural equation modeling. New York City: Guilford Press, 2015.

23. Yuan N, Liu C, Yu L, et al. Study Process of Patients Involved in Treatment Decision-Making State Quo and Influencing Factors. Medicine and Society 2017;30:58-61.

24. Fan X, Liu Z, Sun R, et al. Discussion on the influence of patient safety culture to hospital safety management in China. China: Chinese Hospitals, 2017.

25. Lan G, Ying W, Qian X, et al. Effective observation on prevention for mismatched intravenous infusion by patients' participation in double-identity confirmation. Chinese Journal of Modern Nursing 2012;18:1657-9.

26. Leung GK, Patil NG. Patient safety in the undergraduate curriculum: medical students' perception. Hong Kong Med J 2010;16:101-5.

27. Singer SJ, Gaba DM, Falwell A, et al. Patient safety climate in 92 US hospitals: differences by work area and discipline. Med Care 2009;47:23-31.

28. Seker M. Knowledge of new entrant medical students about medical errors in Selcuk University: an educational perspective. Turkiye Klinikleri J Med Sci 2008;28:217-22.

29. Flin R, Patey R, Jackson J, et al. Year 1 medical undergraduates' knowledge of and attitudes to medical error. Med Educ 2009:43:1147-55.

30. Wetzel AP, Dow AW, Mazmanian PE. Patient safety attitudes and behaviors of graduating medical students. Eval Health Prof 2012;35:221-38.
31. Caldicott CV, Faber-Langendoen K. Deception, discrimination, and fear of reprisal: lessons in ethics from third-year medical students. Acad Med 2005;80:866-73

32. Vohra PD, Johnson JK, Daugherty CK, et al. Housestaff and medical student attitudes toward medical errors and adverse events. Jt Comm J Qual Patient Saf 2007;33:493-501.

33. Madigosky WS, Headrick LA, Nelson K, et al. Changing and sustaining medical students' knowledge, skills, and attitudes about patient safety and medical fallibility. Acad Med 2006;81:94-101.

34. Patey R, Flin R, Cuthbertson BH, et al. Patient safety: helping medical students understand error in healthcare. Qual Saf Health Care 2007;16:256-9.

35. Pearson P, Steven A, Howe A, et al. Learning about patient safety: organizational context and culture in the education of health care professionals. J Health Serv Res Policy 2010;15(Suppl 1):4-10.

36. Walton MM. Hierarchies: the Berlin Wall of patient safety. Qual Saf Health Care 2006;15:229-30.

37. Brainard $\mathrm{AH}$, Brislen HC. Viewpoint: learning professionalism: a view from the trenches. Acad Med 2007;82:1010-4.

38. Lucey C, Souba W. Perspective: the problem with the problem of professionalism. Acad Med 2010;85:1018-24.

39. Tallentire VR, Smith SE, Skinner J, et al. Understanding the behaviour of newly qualified doctors in acute care contexts. Med Educ 2011;45:995-1005.

40. Kiesewetter J, Kager M, Lux R, et al. German undergraduate medical students' attitudes and needs regarding medical errors and patient safety--a national survey in Germany. Med Teach 2014:36:505-10. 